Article

\title{
Acknowledging Children's Voice and Participation in Family Courts: Criteria that Guide Western Australian Court Consultants
}

\author{
Vicki Banham ${ }^{1, *}$, Alfred Allan ${ }^{1}$, Jennifer Bergman ${ }^{2}$ and Jasmin Jau ${ }^{1}$ \\ ${ }^{1}$ School of Arts and Humanities, Edith Cowan University, 6027 Joondalup, Australia; E-Mails: v.banham@ecu.edu.au (V.B.), \\ a.allan@ecu.edu.au (A.A.), jjau@our.ecu.edu.au (J.J.) \\ 2 Department of Attorney General, Family Court Counselling and Consultancy Service, 6000 Perth, Australia; \\ E-Mail: jennifer.bergman@justice.wa.gov.au \\ * Corresponding author
}

Submitted: 30 March 2017 | Accepted: 25 July 2017 | Published: 26 September 2017

\begin{abstract}
The Australian family courts introduced Child Inclusive Conferencing after the country adopted the United Nations Convention on the Rights of the Child. The legislation governing these conferences is minimalistic but the Family Court Consultants in the Family Court of Australia and the Federal Circuit Court have well-developed and documented guidelines. The Family Court of Western Australia is, however, a separate entity and in the absence of regulatory guidelines its Family Consultants developed their own process and criteria. This model is unique, in Australia at least, because it has been organically developed by the practitioners providing the Child Inclusive Conferences with very little, if any, statutory and regulatory guidance. This model therefore serves as an example of how practitioners think child inclusive services should be offered. The model is, however, not documented and the aim of this study was to understand and document Family Consultants' decision making regarding if and when they will conduct a Child Inclusive Conference in the Family Court of Western Australia. Ten Family Consultants were interviewed using semi-structured interviews. A thematic analysis was conducted on the transcripts of the interviews identifying 12 themes. Overall the data suggested that Family Consultants take into account a range of criteria and although they were very cognisant of the importance for the child to be engaged in decision making they noted specific challenges regarding how they could use Child Inclusive Conferencing to do this. These findings provide a basis for the development of regulations that ensure that Child Inclusive Conferences are used optimally to improve the inclusion of children in the family court procedures in Western Australia and potentially elsewhere. Further research is, however, necessary before such regulations can be finalised.
\end{abstract}

\section{Keywords}

children; court; participation; rights; voice of the child

\section{Issue}

This article is part of the issue "Promoting Children's Participation in Research, Policy and Practice", edited by Jo Aldridge (Loughborough University, UK).

(C) 2017 by the authors; licensee Cogitatio (Lisbon, Portugal). This article is licensed under a Creative Commons Attribution 4.0 International License (CC BY).

\section{Introduction}

Australia has since the beginning of the century introduced child inclusive practices in family court processes. Australia did this in part because it is an adoptee of the United Nations Convention on the Rights of the Child (UNCRC) and is therefore guided by Article 12 to involve the child's voice in family court processes. Involvement of the child's voice, was in part, guided by research from two sources. First, research about children's competencies and rights revealed children's desire to be included in the process (Campbell, 2004; Graham \& Fitzgerald, 2010a; James \& Prout, 1997; Mayall, 1994; McIntosh, 2003; Mclntosh, Well \& Long, 2007; Parkinson \& Cash- 
more, 2008; Smart, Neale \& Wade, 2001; Smith, Taylor, \& Tapp, 2003; United Nations, 1989). Second, researchers found that children and adults who participated in a process that involved children, thought it was potentially beneficial to them (Fitzgerald \& Graham, 2011a; Goldson, 2006; Lodge \& Alexander, 2010; McIntosh, 2000, 2003; McIntosh, Wells, Smyth, \& Long, 2008; Moloney \& Mclntosh, 2004). This led to an acceptance in Australia that what is required is not merely an interest in 'listening to the voice of the child' but listening to the voice of the child because they have the 'right to be listened to'.

The Family Court of Australia (FCoA) and the Federal Circuit Court (FCC) responded to the expectations of the UNCRC and the research mentioned above by developing models of child inclusive practice and provided professional directions for delivery pursuant to s11F FLA. The FCoA's Child Responsive Program and the Less Adversarial Trial approach and the FCC's Child Inclusive Conferencing $(\mathrm{CIC})$ both require children to be interviewed at the early stage of their parent's dispute with the view to coming to a more amicable and quicker agreement on the care arrangements (McIntosh et al., 2007). McIntosh et al. (2007) who studied child-inclusive mediations as they occurred in these programs concluded that those who decide when and how the children should be involved should ideally have clear criteria that they apply consistently when they make this determination. This study also called for more dialogue around the setting of professional standards for child consultants (Mclntosh et al., 2007).

However, Western Australia was the only Australian jurisdiction that used s41 of the Family Law Act 1975 (Cwth) to establish a separate State Family Court. Western Australia, by passing the Family Court Act 1975 (WA), which has subsequently been replaced by the Family Court Act of 1997 (WA) (Fogarty, 2001), and created the Family Court of Western Australia (FCWA). The FCWA established the Family Court Counselling Service (FCCCS) that developed its service delivery protocols independently of those used by its counterparts working for the FCoA and the FCC in the rest of Australia. Thus, the FCCCS had to develop its own Child Inclusive Conference model because the procedures uses by the FCWA differs slightly from that used by the FCA and the FCC. The Family Consultants are located within the FCCCS.

Family Court Consultants' (Family Consultants) role is to assist the Family Court to manage child related matters and to obtain the best possible outcomes for children before it. Section (s) 65 of the Family Court Act 1997 (WA) authorises the court to order parties to attend, or arrange for children to attend, appointments with Family Consultants. Courts must seek the advice of Family Consultants before they order these Child Inclusive Conferences (CICs). The court can order CICs on its own initiative or in response to applications by one of the parents or a lawyer that independently represents the interest of children involved in the process. The section provides no further guidance regarding when exactly a
CIC should take place, the role of lawyers in the process, and what the nature of the Family Consultants' reports should be. The section is also silent regarding what the court should do with such reports and their relationship to family reports obtained under s64 of the Family Court Act 1997 (WA) and/or single expert witness (SEW) reports obtained by the parents under the court rules. The Family Consultants therefore developed their own process and usually start by having a Case Assessment Conference (CAC) that involves them doing a thorough risk assessment and preparing case management recommendations that might include, if appropriate, the recommendation of a $\mathrm{CIC}$. CICs are therefore usually standalone events that take place early in the Court process and Family Consultants typically first interview parents and then the children to determine their issues and risks. $\mathrm{CICs}$ therefore serve as preliminary assessments that allow Family Consultants to report to the court and other decision makers the children's views and experiences of their families at an early stage of the process. The Family Consultants' reports are, however, brief unlike the family and single expert witness reports that are based on a full family forensic assessment and further often include material from experts who have been involved with the family or from other government departments.

The minimal statutory guidance and lack of specific regulatory requirements and the small size of the team (there are currently 15 Family Consultants) meant that the $\mathrm{CIC}$ model was developed in an organic rather than systematic manner and that parts of the model have not been well-documented. The FCCCS's model has also not been formally reviewed or evaluated since its introduction in 2012, and the Family Consultants themselves recognise that they lack clear guidelines, to guide them regarding how to involve children. Family Consultants have nevertheless, since 2012, developed a body of accumulated collective wisdom through utilising their individual discretion (drawing upon professional development and experience independent from the FCA and FCC) when choosing to recommend a CIC. The aim of this study was to draw upon this independent accumulated wisdom to seek to document the understandings of Family Consultants when deciding if and when they will conduct a CIC in the FCWA. The purpose of this was to understand the model these practitioners developed so that it can be used to develop clear and well-documented procedures and criteria that will ensure $\mathrm{CIC}$ s serve their purpose of effectively including children into the family court process.

\section{Methodology}

This study was developed from the philosophical assumption that there are multiple realities in the experiences of Family Consultants in deciding when to involve the child in a CIC. Social constructivism, Cresswell (2013), is an assumption that seeks the understanding of an individual's world and their subjective meanings of their 
lived experiences and views. As Family Consultants currently decide on whether or not to involve a child in a $\mathrm{CIC}$ based on their own understandings of the current situation at play, social constructivism was selected as the worldview assumption for this study. This study utilises a phenomenological approach, essentially searching for a common understanding in the phenomenon that the Family Consultant experiences, namely calling upon their independent accumulated wisdom when making a decision to involve or not a child in a CIC. In order to document how they may undertake this decision, the Family Consultants were asked to describe how they independently made this decision.

\subsection{Data Collection}

Data was collected from semi-structured, face-to-face interviews with open-ended questions, where the Family Consultants stated how they independently came to their decisions. After completion of face to face interviews, the interviews were transcribed and preliminary data analysis was undertaken to create a summary of the identified themes from the data. The Family Consultants were then provided with the summary to validate correctness of data gathered, review the identified themes and, provide clarification and or feedback on the identified themes. This feedback was then included in the final data analysis.

\subsection{Ethics}

The protocols for the study were approved by Edith Cowan University Human Research Ethics Committee and the Western Australian Department of the Attorney General.

\subsection{Participants}

In line with a phenomenological approach this study utilised a purposeful sampling strategy, selecting ten Family Consultants who work in the FCWA, ensuring all participants who have experienced the phenomenon contribute their experiences. Ten Family Consultants were selected as these were available at the time of the study and all agreed to participate. The ten Family Consultants in the FCWA were contacted to participate by a senior member of the staff team. Although a small sample size, it is in line with Creswell's (2013), notion who suggests that the size of the sample depends on the qualitative design being undertaken, and phenomenology generally has approximately 3-10 participants.

\subsection{Data Analysis}

The study used a systematic approach to data analysis recommended by Moustakas (1994). The data from the interviews was categorised, and clustered into themes (Creswell, 2013) representing the Family Consultants' comments of how they decided whether or not to initiate a $\mathrm{ClC}$. The themes were then provided to the Family Consultants to review and comment upon. Any feedback received was included in the final data analysis.

\section{Results}

Within the data, twelve core themes were identified: Children's alibility to understand issues and implications and to give feedback; risk; importance of meeting parents first; time factor; hearing the child's voice; focus on resolution; complexity of issues; best interest of the child; opportunity to follow up; therapeutic aspect; practice experience and intuition and the role and the limitations of the role of family consultants. Each of these themes are presented below.

\subsection{Children's Ability to Understand Issues and Implications and to Give Feedback}

Although all Family Consultants considered the age of the child, their cognitive capacity and their knowledge and experience of the situation, the data suggested that generally children from around 10 years are interviewed in $\mathrm{CICs}$ as Consultant $\mathrm{C}$ reported:

Age would be 10 ish and onwards. And why because I know firstly that the court is interested in the voice of the child from that age group. Developmentally they are able to give reasons.

However, some Family Consultants stated that they would interview children who are younger than ten years of age aligning with UNCRC (Lansdown, 2011) that one should begin with the presumption of capacity to contribute. However, they also noted that how much weight is given to the child's voice in court would need to be put into context along with an opportunity for a follow up meeting to see how the arrangements are working for the child. Some Family Consultants explained that they tend to conduct a Family Report (discussed earlier) instead of a CIC if the child is younger. Moreover, in cases where a child is enmeshed in the conflict and has been strongly influenced by the views of one parent, they might not be interviewed as they would not be able to give unbiased feedback. However, it was stated that sometimes it could still be helpful to hear the child's experience even if it is biased.

This is consistent with how the phrases "capable of forming his or her own views" and "according to age and maturity" in the UNCRC (United Nations, 1989, p. 4) were intended. The practices reported by the Family Consultants are in line with the General Comment No. 12, the Committee on the Rights of the Child (Lansdown, 2011; United Nations, 2009) which discourages introduction of age limits and states that age alone cannot determine the significance of a child's views and the views of a child should be assessed on a case by case examination. 
Furthermore, it was explained that if a child would be unable to understand the questioning or give feedback because of developmental delays, intellectual difficulties or a disability, they would not be interviewed. The Family Consultants reported they would not simply rely on the parent's opinions about their child's ability to be interviewed but would want a diagnosis from a doctor or psychologist to confirm.

\subsection{Risk}

Risk or risk of harm and consequences is a serious consideration for Family Consultants. The FCWA FCC Family Consultants usually complete a CAC prior to recommending a $\mathrm{CIC}$. At the CAC a thorough risk assessment is undertaken and if risk is too high a $\mathrm{CIC}$ may not be recommended. CICs are generally recommended for cases where there is a low risk of harm to the child and not recommended if there is an immediate high risk of harm, such as family violence or allegations of sexual abuse or if there are investigations currently underway. However, a matter can go directly to a CIC without a CAC if no or little risk has been identified. Child safety and risks of contaminating the evidence were stated as issues to consider.

However, it was explained that in cases where there is no immediate risk, interviewing could be protective as it provides children with a way to express their views and experiences, which can then be fed back to the parent. For example, where the parent is denying or minimising issues such as mental illness and family violence and the effect it is having on the child. Lastly, it was stressed that sometimes a risk is only identified after speaking to a child as Consultant $C$ reported: "So they give you a different insight to what's really going on."

\subsection{Importance of Meeting Parents First}

Meeting the parents first enables the Family Consultant to seek feedback from the parents on their view of the child's ability and willingness to engage in an interview and whether or not the parents are ready to hear the voice of the child and be guided by it. Such knowledge it was reported assisted in structuring the meeting with the child or children. Consultant $\mathrm{E}$ :

Every time you go into these types of conference having the background information and the knowledge and having some sense of the parents you can structure...questions to the children.... with that in mind. Without it you run the risk of unintendedly putting the child at risk.

Additionally, it was considered a matter of respect to speak to the parents first and state with them the possibility that their child will be interviewed. It was also explained that if there has been contact with the family over a number of years and the Family Consultant knows the family well, they might be more likely to suggest a
$\mathrm{CIC}$ even if there are issues involved such as domestic violence, because they are better able to gauge the risk and benefits of a CIC. Family Consultants also noted that $\mathrm{CICs}$ can sometimes be used as a mediation conference as if parents are less hostile and conflicted Family Consultants might be able to use the child's views as a mediation tool.

\subsection{Time Factor}

$\mathrm{CICs}$ can speed up the court process and move urgent issues through the court quickly. A CIC, undertaken within the first three months of entering the court process, enables the Family Consultant to get to the point quicker and focus on the main issue and avoid unnecessary hearings and delays, reducing unnecessary anxiety and conflict as a drawn out process can increase hostility between the parents. Whereas Family Reports (discussed earlier) questions the child broadly, the $\mathrm{ClC}$ approaches the main issue directly without collecting unrelated information, thus having the potential to bring drawn out conflicts to a resolution. Consultant $F$ explained:

It can also can expedite the court process,...you can jump through a lot of hurdles really quickly if you get the children's views early on in the piece because it makes it really clear for the court and it also can help the parents reach an agreement.

Whilst it was acknowledged that time constraints are a factor, Family Consultants indicated they make their decision based on what is most appropriate for the child and not solely because of limited resources.

\subsection{Hearing the Child's Voice}

It was stated in all interviews that children should have the opportunity to have their voice heard and to express their views and opinions, as Consultant $\mathrm{H}$ reflected: "Your focus is more on the child and the child's right or perspective. Over and above what the parent thinks."

For Consultant I, depending on the situation and the age of the child more or less weight or decision making choices may be given to their views: "They have to have some form of recognition or validation as to their views."

It was noted that sometimes it can be a difficult balance between enabling the child to express their voice while ensuring their safety. The "right to express those views freely" (United Nations, 1989) means that the child can choose whether or not she or he wants to exercise their right to be heard. This was highlighted by Consultant I:

So you really walk a tightrope in terms of trying to hear the child's voice and at the same time trying to protect the child from any conflict or adverse...reactions from the parents. 
It was also explained that while children should have their voice heard, ultimately children prefer that the parents make the final decision, data supported by Parkinson and Cashmore (2008). Lastly, it was emphasised that a child's decision not to participate should be accepted too, as Consultant E stated: "Not wanting to participate is as valid as wanting to participate for a kid's point of view."

\subsection{Focus on Resolution}

A focus on resolution could assist the parents come to an agreement. As Consultant E noted:

Probably the first thing is whether the conference is going to be productive. Is there a possibility of it being productive as in reaching some agreement. Even if the agreement is just to agree to...hearing what the child says and to be guided by it.

Family Consultant's stated that where parents have opposing views on what is in the best interest of the child or where they are so enmeshed in long-standing disputes, the child's voice gets lost. Interviewing the child can provide more insight into what the child's views and opinions actually are, which is important for the court to know before making any orders.

This response from the Family Consultants highlights the argument postulated by Fitzgerald and Graham (2010b) and Graham and Fitzgerald (2011a) that the criteria of parent readiness (to hear what the child wants/says about what is happening) can be problematic as it can potentially lead to the child being excluded from the process. It has also been suggested that parent readiness to listen should be assessed to determine the level of the child's involvement and how it could be useful, as opposed to deciding if the child should be involved at all (Fitzgerald \& Graham, 2011b), being the Family Consultants aim in undertaking a CIC.

\subsection{Complexity of Issues}

Generally, as discussed earlier, the tendency is to recommend a $\mathrm{CIC}$ in cases where the issue is a simple or very concrete with minimal risk, such as a name change, travel or a decision about what school the child should attend. For more complex issues or where there is a higher risk a Family Report (discussed earlier) might be conducted as in cases where there are issues such as significant family violence, substance abuse or mental health issues, to enable the issues to be unpacked and explored in depth.

However, it was pointed out that there are exceptions to these criteria and that every case is different and has to be assessed individually. Moreover, the relationship of the parents is also taken into consideration and Family Consultants (discussed earlier) would be more likely to recommend a CIC in cases where the parent's relationship is less hostile and conflicted.

\subsection{Best Interest of the Child}

Best interest, and safety and wellbeing of the child appeared paramount to Family Consultants, in line with both the UNCR and Family Law Legislation. As discussed earlier, if there are high risks or if there are likely repercussions for the child in expressing their views, then a CIC would not be recommended. Consultant $\mathrm{H}$ states:

First consideration is what are the consequences for...this child if this child is involved in this conversation and how can it work. I mean in a child inclusive you....be trying to talk to the parents you want that conversation to be a change agent really....You can't do that if they're not cooperating.

Furthermore, Family Consultants stated they would generally not undertake a $\mathrm{CIC}$ with a child who have been interviewed multiple times in the recent past, for example by a single expert (as discussed earlier), unless some major change had occurred, as multiple interviewing can put stress and pressure on the child.

The subject of multiple interviewing children is addressed by the UNCRC (Lansdown, 2011; O'Neill \& Zajac, 2013) which acknowledges that "hearing a child's voice" is a difficult process that can have a traumatic impact on the child and emphasises the importance of avoiding unnecessarily reinterviewing children. Family Consultants also consider how much weight the court might give to the child's views to avoid the child being interviewed and then not listened to and feeling let down. If an order was made by the court to interview the child anyway the Family Consultant would ask the parents to prepare the child to minimise any negative impact.

\subsection{Opportunity to Follow Up}

The potential to conduct a follow-up meeting, which may influence their decision making was considered a positive, as Consultant I reported:

I'm thinking you can maybe do two or three Child Inclusives and I think that can give you a better result than having one family report....You get more of a longitudinal view of how everything is tracking.

It was expressed that Family Consultants, in some cases, find it concerning if decisions are made based on a document that was produced after one single conference with a child, as this can only ever capture the child's views on that particular day.

Furthermore, it was stated that a child might express very negative feelings towards one parent because they want to ensure they get to live with the other parent. However, once they have the desired living arrangement these negative feelings could subside. Moreover, it was explained that follow-up conferences enable trialling of matters, such as living arrangements, so adjustments 
can be made and any risks be identified that have been missed earlier. Usually CICs are one off events but the Family Consultants can recommend further or follow up $\mathrm{CICs}$ if they feel the child would benefit from it, an example being reviewing a change of spent time or living arrangements.

\subsection{Therapeutic Aspects}

CICs are more flexible and friendly and are less forensic and adversarial assessments than the Family Reports (discussed earlier). Family Consultants are able to tailor $\mathrm{CICs}$ to the individual family and use it as a mediation tool with the parents. Furthermore, CICs can make the court process easier and achieve a more child focused process, as it enables the Family Consultants to work with a family over a period of time and prepare them for the court process. Consultant $\mathrm{C}$ explored this further stating:

And it is therapeutic when they do hear the views of the child. The way that we reframe it to the parents it can be quite therapeutic. Especially families who don't really talk often. So you're actually bringing them in the room together and you're reframing... what it's like for that child....Parents are seeing it on a different level. It brings a lightbulb moment sometimes.

Thus, providing the opportunity for a child to be included and to give his/her view can help parents gain insight and to motivate them take necessary steps such as attending a family violence course to ensure the child feels safe when spending time with them.

CICs can also help parents to feel that they are more involved and help them gain a better understanding of the situation which helps ease anxiety. Lastly, the issues that the parents are trying to resolve might not be the issues that the child is concerned about but through a $\mathrm{CIC}$ will only become apparent if the child has an opportunity to express their views.

\subsection{Practice Experience and Intuition}

It was explained, by three Family Consultants that on occasion the decision to conduct a $\mathrm{CIC}$ can be intuitive, that often decision making is inherent from practice experience rather than a conscious application of set criteria, as Consultant $\mathrm{H}$ reports:

I think it is really good to externalise this as well. So many of our decision making is inherent-it just comes from your practice wisdom. But you need to stop and go hang on why? So I think that's really important that we do this.

Family Consultants are social workers and psychologists and as such have extensive training and expertise in working with families so such responses, as Consultant
$\mathrm{H}$ refers to, may possibly be related to their experience in the role working in the FCWA.

\subsection{Role of Family Consultants and Limitations of Role}

The data suggests that Family Consultants perform relatively basic interviewing which can often be more helpful than a single expert interview. However, if there are issues such as a high risk, alienation by one parent, parents unwilling to listen and cooperate, or a child with special needs, then it could be more appropriate for a single expert to interview as Consultant B explained:

They should be heard but maybe just we're not entirely the best people to hear that...where there's these special requirements.

It was stated that on some occasions where an Independent Children's Lawyer (ICL) has already interviewed the child, it might be unnecessary for a Family Consultant to interview as well. Such factors placed limitations on the role of the Family Consultant as their focus at all times is best interest, safety and wellbeing, and the implications for the child being interviewed. Thus, in some circumstances they reported it would not be in the best interest of the child to conduct a CIC. It was stated that if the $\mathrm{ICL}$ is clear on the views of the child and what it is they want then there is no point in ordering a $\mathrm{CIC}$. If the issue is more complex, then a Family Report will be ordered.

\subsection{Summary of Themes}

A thematic analysis of the data from the interviews with the Family Consultants identified twelve themes which were at times interrelated suggesting there is a range of criteria that impact on how the Family Consultants make decisions. Family Consultants are focused on ensuring the safety and wellbeing of the children and are conscious of the potential risk for children to be included in a conference. This, along with the complexity of the issues involved, Family Consultants were even more focussed on the need to assess for risks, including stress caused through participation in the interview process, and to achieve the most positive outcome for the child. This is in line with the literature that suggests that child inclusive processes must balance the right of the child to be heard with the responsibility to ensure the child's safety and that it is not always in the child's best interest to give their views (Fernando, 2014; Henry \& Hamilton, 2012; Roeback \& Hoejer, 2009). Furthermore, the Family Consultants suggest that to truly listen to the views of the child, the child needs to have a more substantial role in identifying and determining what their best interests are and deciding what matters that affect them are (Banham, Guilfoyle, Lincoln, \& Cavazzi, 2011). The Family Consultants reported they considered in their decision making how much weight the court might give to the child's views to avoid the child being interviewed and then not 
listened to and feeling let down. Family Consultants appear to balance the best interest of the child with Article 12 which outlines the right of the child to express their views in all matters that affect them. The opportunity to meet with the parents first before making a decision to involve a child to get a sense of parent views, so as to gauge risks and benefits of including a child, is important as it enables them to collect as much information as possible to support the child. The CIC can be used to bring resolution to the issues; an opportunity to follow up to clarify any concerns; as a therapeutic tool to collaborate, build relationships; and put the parent and child at ease with the court process. More importantly, the data identified that Family Consultants are conscious of their decision making process; the role that practice experience and intuition play; and the importance of reflection and understanding why such decisions are made. Overall, Family Consultants were very aware of their role and the scope of their role and when necessary initiated other avenues, such as recommending a single expert interview, to ensure the child's voice is heard.

\section{Conclusion}

The results of this study reflect the Family Consultants' development of a process and criteria (model) that allow them to achieve the aims of CICs as they understand them in the absence of explicit regulatory guidance. The model they developed appears to fit the organisational structure and requirements of the Family Court of Western Australia and serves to make CICs effective methods of determining and reflecting children's views at an early stage of the process. The importance of the model is that it was developed by practitioners who actually work towards ensuring children's views are reflected in the legal process from an early stage and that they did this with very little statutory and regulatory guidance. This process and criteria could therefore serve as a starting point to develop a regulatory framework to guide Family Consultants, the court, parties and their lawyers in Western Australia, but also in other jurisdictions. CICs are, however, only one small part of the proceedings in the court and despite Family Consultants' pivotal role they are also only one small group of people involved in these proceedings. Those developing statutory and regulatory provisions will therefore also have to take into account the experiences and views of children, parents, judiciary and other stakeholders if they want to develop a CIC process that leads to the optimal representation of children's views. Researchers must therefore ideally undertake research that establishes how children, parents, courts and lawyers believe the $\mathrm{CIC}$ process can be most effectively used to ensure that children are included in the process in a safe manner. Researchers should specifically identify the weight of Family Consultants' reports in comparison with the family and single witness expert reports and how differences between these reports should be reconciled.

\section{Acknowledgements}

This study acknowledges funding from the School of Arts and Humanities, collaboration with the Family Consultants in the Family Court of WA, and the Department of Attorney General.

\section{Conflict of Interests}

The authors declare no conflict of interests.

\section{References}

Banham, V., Guilfoyle, A., Lincoln, R., \& Cavazzi, T. (2011). Parental separation and the right of the child to have their views listened to and considered: Reality or wishful thinking? International Journal of Learning, 17(11), 495-508.

Campbell, A. (2004). The voice of the child in family law: Whose right? Who's right? (PhD Disssertation). University of South Australia.

Creswell, J. (2013). Research design. Qualitative, quantitative, and mixed methods approaches (4th Ed.). Thousand Oaks, CA: SAGE Publications.

Family Law Act 1975 (Cwth). [online] Retrieved from: https://www.legislation.gov.au/Details/C2016C01106

Family Court Act 1997 (WA). [online] retrieved from https://www.slp.wa.gov.au/legislation/statutes.nsf/ main_mrtitle_321_homepage.html

Fernando, M. (2014). Family law proceedings and the child's right to be heard in Australia, the United Kingdom, New Zealand, and Canada. Family Court Review, 52(1), 46-59.

Fitzgerald, R., \& Graham, A. (2011a). "Something amazing I guess!" Children's views on having a say about supervised contact. Australian Social Work, 64(4), 487-501.

Fitzgerald, R., \& Graham, A. (2011b). The changing status of children within family law from vision to reality? Griffith Law Review, 20(2), 421-448.

Fogarty, J. (2001). Establishment of the Family Court of Australia and its early years: A personal perspective. Family Matters, 60, 90-99.

Goldson, J. (2006). Hello, I'm a voice, let me talk. Childinclusive mediation in family separation. Families Commission, Innovative practice report No.1/06.

Graham, A. \& Fitzgerald, R. (2010a). Exploring the promises and possibilities for children's participation in Family Relationship Centres. Family Matters, 84, 53-60.

Graham, A., \& Fitzgerald, R. (2010b). The changing landscape of family law: Exploring the promises and possibilities for children's participation in Australian Family Relationship Centres. Family Matters, 53(84), 53-60.

Henry, P., \& Hamilton, K. (2012). The inclusion of children in family dispute resolution in Australia: Balancing welfare versus rights principles. International Journal of Children's Rights, 20, 584-602. 
James, A., \& Prout, A. (1997). Constructing and reconstructing childhood: Contemporary issues in the sociological study of childhood (2nd ed.). UK: The Falmer Press.

Lansdown, G. (2011). Every child's right to be heard: A resource guide on the UN Committee on the rights of the child general comment no. 12. London: Save the Children.

Lodge, J., \& Alexander, M. (2010). Views of adolescents in separated families. Melbourne, Australia: Australian Institute of Family Studies.

Mayall, B. (1994). Children's childhoods: Observed and experience. London: The Falmer Press.

Mclntosh, J. E. (2000). Child inclusive divorce mediation: Report on a qualitative research study. Mediation Quarterly, 18(1), 55-59.

McIntosh, J. E. (2003). Enduring conflict in parental separation: Pathways of impact on child development. Journal of Family Studies, 9(1), 63-80.

McIntosh, J. E., Wells, Y., \& Long, C. (2007). Child focused and child inclusive family law dispute resolution: One year findings from a prospective study of outcomes. Journal of Family Studies, 13, 8-25.

McIntosh, J. E., Wells, Y. D., Smyth, B. M., \& Long, C. M. (2008). Child-focused and child-inclusive divorce mediation: comparative outcomes from a prospective study of post separation adjustment. Family Court Review, 46(1), 105-124.
Moloney, L., \& Mclntosh, J. E. (2004). Child responsive practices in Australian family law: Past problems and future directions. Journal of Family Studies, 10(1), 71-78.

Moustakas, C. (1994). Phenomenological research methods. Thousand Oaks, CA: SAGE Publications.

O'Neill, S., \& Zajac, R. (2013). The role of repeated interviewing in children's responses to cross-examinationstyle questioning. British Journal of Psychology, 104(1), 14-38.

Parkinson, P., \& Cashmore, J. (2008). The voice of a child in family law disputes. Oxford: Oxford University.

Roeback, K., \& Hoejer, I. (2009). Constructing children's views in the enforcement of contact orders. International Journal of Children's Rights, 17, 663-680.

Smart, C., Neale, B., \& Wade, A. (2001). The changing experience of childhood: Families and divorce. Cambridge, MA: Polity Press.

Smith, A., Taylor, N. \& Tapp, P. (2003). Rethinking children's involvement in decision making after parental separation. Childhood, 10(2), 201-206.

United Nations. (1989). United Nations convention on the rights of the child. Retrieved from http://www. ohchr.org/en/professionalinterest/pages/crc.aspx

United Nations. (2009). General comment, No 12. The right of the child to be heard. Retrieved from: http:// www2.ohchr.org/english/bodies/crc/docs/Advance Versions/CRC-C-GC-12.pdf

\section{About the Authors}

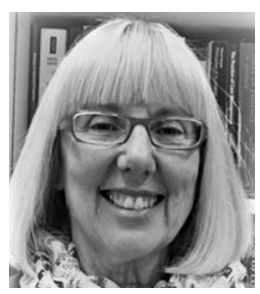

Vicki Banham is Associate Dean (Social Science, Social Work, Counselling, Youth Work) in the School of Arts and Humanities, Edith Cowan University. She teaches in the vulnerable people and communities; and social analysis space. Research interests lie in the role of active participation in society; and rights of vulnerable people, groups and communities. Holder of a Vice Chancellor's Award in Excellence in Teaching and Learning, Executive Dean's Award and from 2002-2012 a Commonwealth Ministerially appointed position as Chair Accreditation Decisions Review Committee.

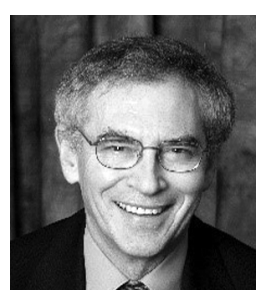

Alfred Allan is qualified in law and psychology and is a registered psychologist with clinical and forensic endorsements in Australia. He is Professor in psychology at Edith Cowan University in Perth Australia and has previously taught law, psychology and professional ethics in Law and Medical faculties in South Africa. He is the author of several book chapters and books and publishes widely in ethics, law, psychology and psychiatry journals and serves on the editorial committee of several journals.

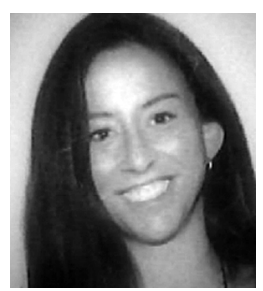

Jennifer Bergman is a Senior Social Worker/Family Consultant at the Family Court of Western Australia. Her background is in the social work space and she has worked in Child Protection, Community Corrections, and as a Trauma Counsellor with the Family Violence and Victim Support Service at the Department of the Attorney General, Western Australia. 


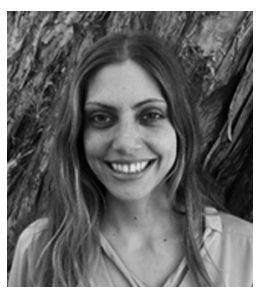

Jasmin Jau is a research assistant and academic tutor (Aboriginal Tuition and Mentoring Program) at Edith Cowan University in Western Australia. Research areas and interests include children's rights, mental health, social inclusion and social justice, animal interaction and social work education. In her honours research Jasmin explored the experience of the benefits of interaction with animals to mental health. Jasmin also currently works with young people in a residential mental health recovery program. 